\title{
Mesto na prehodu
}

\section{Mirko Pak}

Dr., Oddelek za geografijo, Filozofska fakulteta, Univerza v Ljubljani, Aškerčeva 2, 1000 Ljubljana, Slovenija e-mail: mirko.pak@ff.uni-lj.si

\section{Izvleček}

Slovenska mesta doživljajo podobne razvojne trende kot mesta razvitih držav, ki vodijo v vse večjo funkcijsko in socialno heterogenost. Na primeru Ljubljane in Maribora so prikazani posamezni procesi v mestnih središčih, v sklenjeno pozidanem mestnem teritoriju in $v$ obmestjih. Na koncu je opredeljena funkcija geografije $v$ proučevanju in iskanju poti za skladnejši regionalni razvoj mest.

Ključne besede: mesto, obmestje, urbanizacija, socialna sestava, funkcijska zgradba, prostorski razvoj, Ljubljana, Maribor

\section{City at Transition}

\begin{abstract}
Development trends of Slovene cities are similar to those in developed countries, which result in bigger and bigger functional and social heterogeneity. Certain processes in city centres, at continuously built-up city teritorry and outskirts, are represented on the examples of Ljubljana and Maribor. At the end, function of geography in relation to studying and searching for ways in respect of more harmonious development of cities is defined.
\end{abstract}

Key words: Cities, outskirt, urbanisation, social structure, functional structure, spatial development, Ljubljana, Maribor 


\section{EKSPANZIJA MEST}

Urbanizacija je eden najpomembnejših kompleksnih prebivalstvenih in naselbinskih procesov v svetu. $\mathrm{V}$ razvitih državah živi v mestih že več kot $76 \%$ vsega prebivalstva, v državah v razvoju pa $40 \%$. Za ta proces koncentracije je značilna tako rast malih kot srednje velikih in še posebej velikih mest, med katerimi rastejo skupaj s svojimi obmestji in celo aglomeracijami najhitreje največja mesta. Čeprav velja to za vse celine in države, pa je treba izpostaviti nagel razvoj mest v državah v razvoju in v post socialističnih državah. Danes najdemo med desetimi največjimi mesti na svetu le še kakšno iz razvitih držav (Holzner, 2001).

Tabela 1. Deset največjih mest na svetu

\begin{tabular}{|c|l|l|r|r|}
\hline Mesto & Okrog 1700 & Okrog1900 & 1997(mil.preb.) & 2015(mil. preb.) \\
\hline 1 & London & London & Tokio $(21,6)$ & Tokio $(28,7)$ \\
\hline 2 & Paris & New York & New York $(16,0)$ & Bombay $(27,3)$ \\
\hline 3 & Lizbona & Paris & L. Angeles $(15,5)$ & Lagos $(24,4)$ \\
\hline 4 & Amsterdam & Berlin & Mexico C. $(15,0)$ & Shanghai $(23,4)$ \\
\hline 5 & Rim & Chicago & Bombay $(12,6)$ & Jakarta $(21,1)$ \\
\hline 6 & Madrid & Philadelphia & Buen. Aires $(11,3)$ & Sao Paolo $(20,8)$ \\
\hline 7 & Neapelj & Tokio & Kalkutta $(11,0)$ & Karači $(20,6)$ \\
\hline 8 & Benetke & Dunaj & Seul $(10,2)$ & Peking $(19,4)$ \\
\hline 9 & Milano & S. Petersburg & Sao Paulo $(10,0)$ & Daka $(19,0)$ \\
\hline 10 & Palermo & Manchester & Paris $(9,3)$ & Mexico C. $(18,8)$ \\
\hline
\end{tabular}

Vir: Klaus Zehner, Megastaedte - Weltstaedte-Hauptstaedte, GR 2002/10.

Pospešena urbanizacija je povezana $\mathrm{z}$ intenzivno suburbanizacijo ter iz tega izhajajočo rastjo aglomeracij ali urbanih regij. Te se prostorsko širijo in strukturno zgoščajo vključujoč satelitska mesta, pri čemer postaja obmestje sklenjeno pozidano območje vedno bolj nedefiniranega mestnega obrobja. Pri tem pa centrifugalne sile in terciarizacija vodita $\mathrm{v}$ zmanjšanje števila prebivalstva $\mathrm{V}$ ožjem mestu, ki v najboljšem primeru stagnira (Diagram). Podobni razvojni procesi se odvijajo tudi v slovenskih mestih in še posebej v Ljubljani. In ker se vedno bolj uveljavljata tudi reurbanizacija in gentrifikacija je povečano tudi zanimanje za bivanje $\mathrm{v}$ mestnem središču. Mesta postajajo vedno bolj poli funkcionalni prostor, za kar je lep primer predel med Kotnikovo in Masarykovo cesto blizu železniške postaje v Ljubljani. 
Diagram 1: Rast prebivalstva v zahodno-nemških aglomeracijah

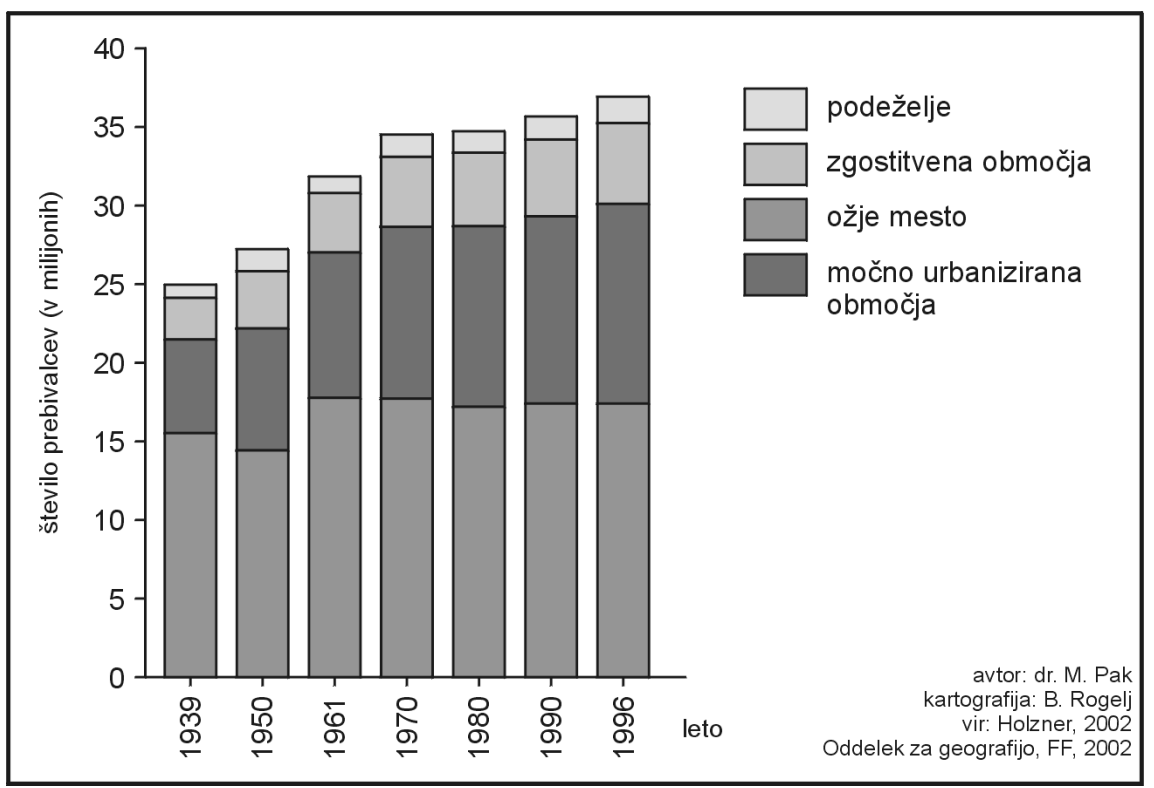

Vedno bolj se poglablja tudi hierarhija mest od največjih mega mest navzdol. Ekonomska moč mest raste premo sorazmerno z njihovo velikostjo, temu sledi tudi urbanizacija in prostorsko širjenje aglomeracij. Največja mesta krepijo svojo funkcijo nosilcev ekonomske in s tem tudi razvojne moči. Zanje je zato tudi največ raziskovalnega zanimanja. Razvrščajo jih v tri osnovne skupine:

Megacity (mega mesto) $\mathrm{z}$ več kot 8 milijonov prebivalcev, $\mathrm{v}$ katerih živi že $10 \%$ svetovnega prebivalstva.

Metropole kot aglomeracije $\mathrm{z}$ več kot 1 milijonom prebivalcev; $\mathrm{v}$ Avstraliji živi v njih že nad $50 \%$, v ZDA pa nad 36,2\% vseh prebivalcev.

Globalna mesta (Global Cities) s posebnimi ekonomskimi značilnostmi, ekstremno koncentracijo denarnega trga, proizvodnje, trgovine, politike. Kot taka so središča odločanja. $Z$ razvojem tehnologije, transporta, informatike se njihov položaj še nadalje krepi. Postajajo centri svetovnega gospodarstva.

\section{PROCESI V MESTU}

Če so bili v prejšnjih desetletjih razvojni procesi v mestih dokaj transparentni, danes temu ni več tako. Prepoznavne časovne razvojne zakonitosti, ko so se menjavali periferno-središčni odnosi, močno prepleteni s socialnimi dejavniki, 
so danes veliko bolj zapletene. V razvoju mest se skoraj enakovredno uveljavljajo vsi ali več procesov hkrati in ti vedno bolj temeljijo na ekonomskih dejavnikih. To so naslednji procesi:

- globalizacija kot prevladujoč proces vedno močnejše ekonomske koncentracije in specifičnih ekonomskih soodvisnosti pod vplivom velikih centrov moči;

- counterurbanization, ki pomeni selitev dejavnosti in prebivalstva iz mesta na podeželje, nemalokrat tudi na oddaljeno obrobje; s tem povezana

- deurbanizcija, ki pomeni nazadovanje števila prebivalstva in delovnih mest $\mathrm{v}$ urbanem prostoru, še posebej $\mathrm{v}$ mestnih središčih in nemalokrat tudi v suburbanih zonah;

- gentrifikacija, ki označuje rast vrednosti mestnega središča tako za prebivalstvo kot za terciarni sektor,

- reurbanizacija pomeni hitrejšo rast prebivalstva $\mathrm{v}$ mestnih središčih $\mathrm{v}$ primerjavi z mestnim obrobjem, kar je še posebej podprto z manjšimi prometnimi stroški, ter

- suburbanizacija kot urbanizacija obmestja, mestoma tudi širšega območja, $\mathrm{z}$ naraščajočim preseljevanjem prebivalstva in dejavnosti iz mesta.

Prepletanje navedenih razvojnih procesov ustvarja silen pritisk na rabo mestnega prostora, posledica pa je vedno bolj mešana raba, oziroma prepletanje bivalne in drugih funkcij.

\section{SLOVENSKA MESTA NA PREHODU}

Živahne strukturne in prostorske spremembe spremljajo tudi razvoj slovenskih mest, ki so zaradi polne uveljavitve ekonomskih dejavnikov še toliko bolj vidne, od tistih v socialni in funkcijski zgradbi do prostorskih posegov. Da v tem večja in gospodarsko močnejša mesta prednjačijo je seveda razumljivo. To pa pomeni tudi hitrejšo rast delovnih mest in večji vpliv na svojo okolico. Med številnimi razvojnimi dejavniki pa so v ospredju prehod na tržno gospodarstvo, zasebna in lokalna iniciativa, denacionalizacija in reprivatizacija, investicijska politika, "globalizacija" in drugo.

\subsection{Socialna zgradba}

Na splošno se bivalni pogoji v naših mestih izboljšujejo, predvsem na račun boljše komunalne in še posebej oskrbne infrastrukture, deloma tudi zaradi večje ekološke osveščenosti, kar pa vse tudi pomeni spreminjanje bivalne vrednosti. To najbolj povečujejo novogradnje in vsakovrstne sanacije, ki se mnogo 
bolj kot $\mathrm{v}$ preteklosti pojavljajo na celotnem mestnem teritoriju. Eden najlepših primerov je nedvomno revitalizacija Lenta v Mariboru, ki je ta mestni predel povsem prevrednotila ter spremenila njegovo socialno in funkcijsko zgradbo. Najnovejša gradnja nadstandardnih stanovanj na severo-zahodnem obrežju Drave potrjuje naraščanje vrednosti določenih, v prvi vrsti najbolj "atraktivnih" lokacij v mestnem središču.

$\mathrm{V}$ mestnih središčih in podobno tudi v mestnih jedrih prebivalstvo zaradi pospešene terciarizacije številčno še nadalje nazaduje, kar pa zaradi povečane bivalne vrednosti ne spremlja tudi nazadovanje starostne, izobrazbene in ekonomske strukture prebivalstva. Poleg vsesplošnega večanja bivalne privlačnosti mestnega središča sta glavna razloga temu predvsem denacionalizacija in pospešena gradnja prostih površin, ki je $\mathrm{v}$ mestnem središču največkrat večnamenska, tudi z znatno bivalno funkcijo. Mestno središče je zato sicer območje znatnega odseljevanja, obenem pa tudi priseljevanja in prestrukturiranja prebivalstva.

$\mathrm{Z}$ denacionalizacijo in povečanim zanimanjem za bivanje $\mathrm{v}$ mestnih središčih je povezana revitalizacija vil. Njihova lokacija na robu mestnega središča je zaradi dostopnosti še posebej privlačna. Mlado prebivalstvo v njih ostaja, vračajo se potomci, zanje pa se zanimajo tako gospodarski kot negospodarski subjekti. Učinki tega so vidni v njihovi revitalizaciji, spremembi rabe. Značilne spremembe doživlja sklenjen vilski predel na severnem obrobju mestnega središča Maribora, še posebej pa bolj ali manj intenzivno kar številni vilski predeli v Ljubljani. Ob krčenju stanovanjske funkcije, se v vilskih predelih socialna strukura izboljšuje.

Vilskim predelom podobne trende doživljajo ljubljanske Murgle, ki zaradi skromnih stavb in poslabšanja bivalnega okolja (promet, hrup, onesnažen zrak) sicer na splošno ne veljajo več za elitno četrt, vendar zaradi njihove ugodne lege in pomanjkanja stanovanj pritegujejo mlado prebivalstvo. Zunanji odsev socialne revitalizacije se kaže v obnovi in dogradnji hiš.

Poseben razvojni trend predstavljajo nove blokovske soseske, namenjene predvsem mlademu in ekonomsko dobro stoječemu prebivalstvu na sklenjeno pozidanem mestnem teritoriju ali na njegovem obrobju, kot so v Ljubljani med drugim Nove Poljane, Bežigrajski dvor in Koseze. Prinašajo novo socialno kvaliteto $\mathrm{v}$ mesto, prispevajo pa bistveno $\mathrm{k}$ njegovi strukturni pestrosti. V vsakem primeru pa predstavljajo novo kvalitetno kategorijo blokovskih naselij in jih lahko primerjamo s podobnimi gradnjami $\mathrm{v}$ mestih gospodarsko razvitih evropskih držav v smislu približevanja bivanja in delovnega mesta.

Suburbanizacija je tudi značilnost slovenskih mest. Bivalni funkciji se je $\mathrm{v}$ obmestju pridružila terciarna funkcija, ki je funkcionalno vezana na mestno prebivalstvo. In ker gre tudi v tem primeru za suburbanizacijo bivanja in dela, raste v obmestjih tako število prebivalstva kot število delovnih mest. 
Navedeni in še drugi najnovejši razvojni procesi $\mathrm{v}$ naših mestih spreminjajo njihovo socialno sestavo, seveda močneje $\mathrm{v}$ večjih kot $\mathrm{v}$ manjših mestih, v čemer Ljubljana močno prednjači. Predvsem pa postaja socialna sestava mesta vse bolj pestra, spremenjeni vrednosti posameznih mestnih predelov se prilagaja tudi socialna sestava, izboljšuje se socialna sestava mestnega jedra in celotnega mestnega središča. Podobnim trendom sledimo tudi v obmestjih.

\subsection{Funkcijska zgradba}

Ekspanzija terciarnih dejavnosti vodi $\mathrm{v}$ vedno bolj pestro rabo mestnega prostora. $Z$ izjemo redkih sosesk enodružinskih hiš, v katerih se še ni močneje razmahnila terciarizacija in blokovskih sosesk, $\mathrm{v}$ katerih se je še posebej razvila oskrbna infrastruktura, je večina drugih predelov ali celo uličnih blokov funkcijsko vedno bolj mešanih. Lep primer je stara Šiška v Ljubljani z manjšimi storitvenimi in celo proizvodnimi obrati in na drugi strani prav tako v Ljubljani Beži$\operatorname{grad} \mathrm{z}$ večjimi nestanovanjskimi objekti pestre sestave. (Karta 1)

Karta 1: Primer funkcijske pestrosti za Bežigradom v Ljubljani

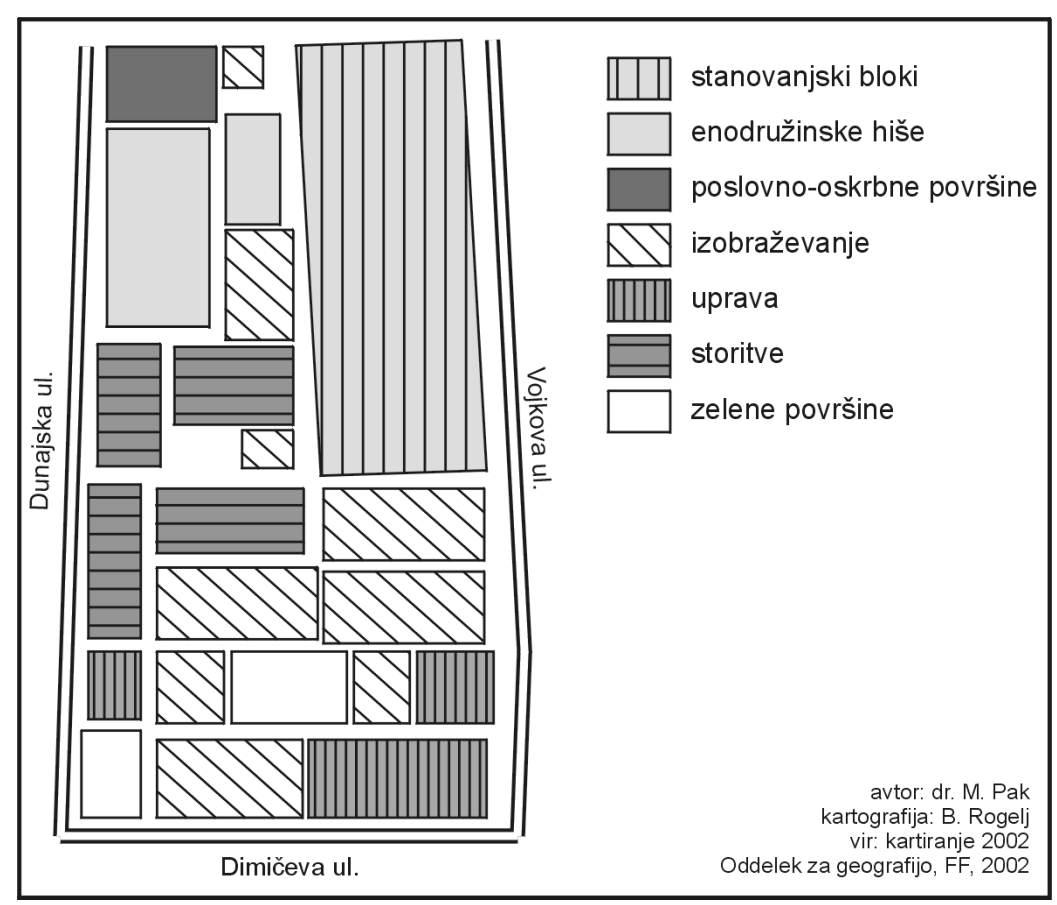


Posebno obliko terciarizacije predstavlja gradnja velikih oskrbnih objektov ali celo oskrbnih središč. Ta se vedno bolj selijo na obrobje mesta, se širijo in funkcijsko dopolnjujejo.Število različno velikih oskrbnih središč se množi brez kakršnih koli zakonitosti, brez posebne strukturiranosti in brez prepoznavnega vplivnega območja, ki se oblikuje največkrat glede na ugodnost ponudbe in se dejansko v številnih primerih tudi hitro spreminja. Glede na to so se močno povečale oskrbne površine, $v$ Ljubljani od $131000 \mathrm{~m}^{2}$ leta 1986 na $327000 \mathrm{~m}^{2}$ leta 2000. V Ljubljani lahko govorimo o štirih glavnih koncentracijah oskrbe, Merkator centru na zahodnem robu mesta, BTC na severo-vzhodnem robu, center na Rudniku na jugo-vzhodnem del in Interspar na južnem robu mesta. $\mathrm{V}$ vseh primerih gre za položaj na stiku sklenjeno pozidanega mestnega prostora in obsežnega obmestnega vplivnega območja, v katerem prav zaradi tega zaostaja razvoj oskrbne funkcije v lokalnih središčih (Pak, 2002). (Karta 2)

Razvoj oskrbne infrastrukture na mestnem obrobju in še kje, je močno prizadel oskrbne obrate v mestnem središču. Marsikje se je zmanjšalo njihovo število, trgovine se hitro menjavajo, specializirajo in močno prizadeta so nekatera manjša oskrbna središča. Med drugimi doživlja težave center Ledina v Ljubljani, zaprli so veleblagovnico Metalka, v Mariboru pa veleblagovnico Merkur. Številni obrati zlasti v mestnih središčih menjavajo lastnika ali najemnika, številni pa spreminjajo svojo dejavnost. Ker je mestno središče lokacijsko še vedno zanimivo za trgovino, male trgovine zamenjujejo večje in močnejše firme.

Srednjeveško mestno jedro Ljubljane doživlja nadaljnjo terciarizacijo na račun stanovanjske funkcije. $\mathrm{K}$ temu močno prispeva denacionalizacija, ki je $\mathrm{z}$ novimi-starimi lastniki prinesla tudi nove ekonomske interese. $\mathrm{V}$ zadnjem desetletju se je povečalo število terciarnih obratov, predvsem trgovin za srednjeročno oskrbo in gostinskih lokalov, poglablja se specializacija, pomnožilo se je število obratov na Gornjem trgu in nekatere stavbe v celoti izgubljajo stanovanjsko funkcijo. Množita se tudi kulturna ponudba in uprava. Tako postaja ljubljansko mestno jedro po svoji rabi vedno bolj podobno mestnim jedrom drugih srednje evropskih mest (Karta 3). Splošna kriza mestnih jeder pa se v Ljubljani kaže še najbolj v nadpovprečni menjavi najemnikov lokalov, saj se jih je $\mathrm{v}$ zadnjih letih zamenjala tretjina, $\mathrm{v}$ spreminjanju njihove sestave in $\mathrm{v}$ relativno nizkih najemninah, kar vse velja tudi za celotno mestno središče.

Za Ljubljano je značilna pospešena citizacija. Če je bila ta že dolgo vidna po višini stavb in po njihovi namembnosti, se zadnja leta močno zgošča ob Dunajski cesti in v nekem pogledu sega že do mestne obvoznice na severu, kjer se na ta način namešča veliko število delovnih mest. Cityzacija mestnega središča se bo vsekakor še okrepila in razširila tudi na južni rob glavne poslovno-trgovske osi Ljubljane ob Dunajski-Slovenski in Barjanski cesti. 


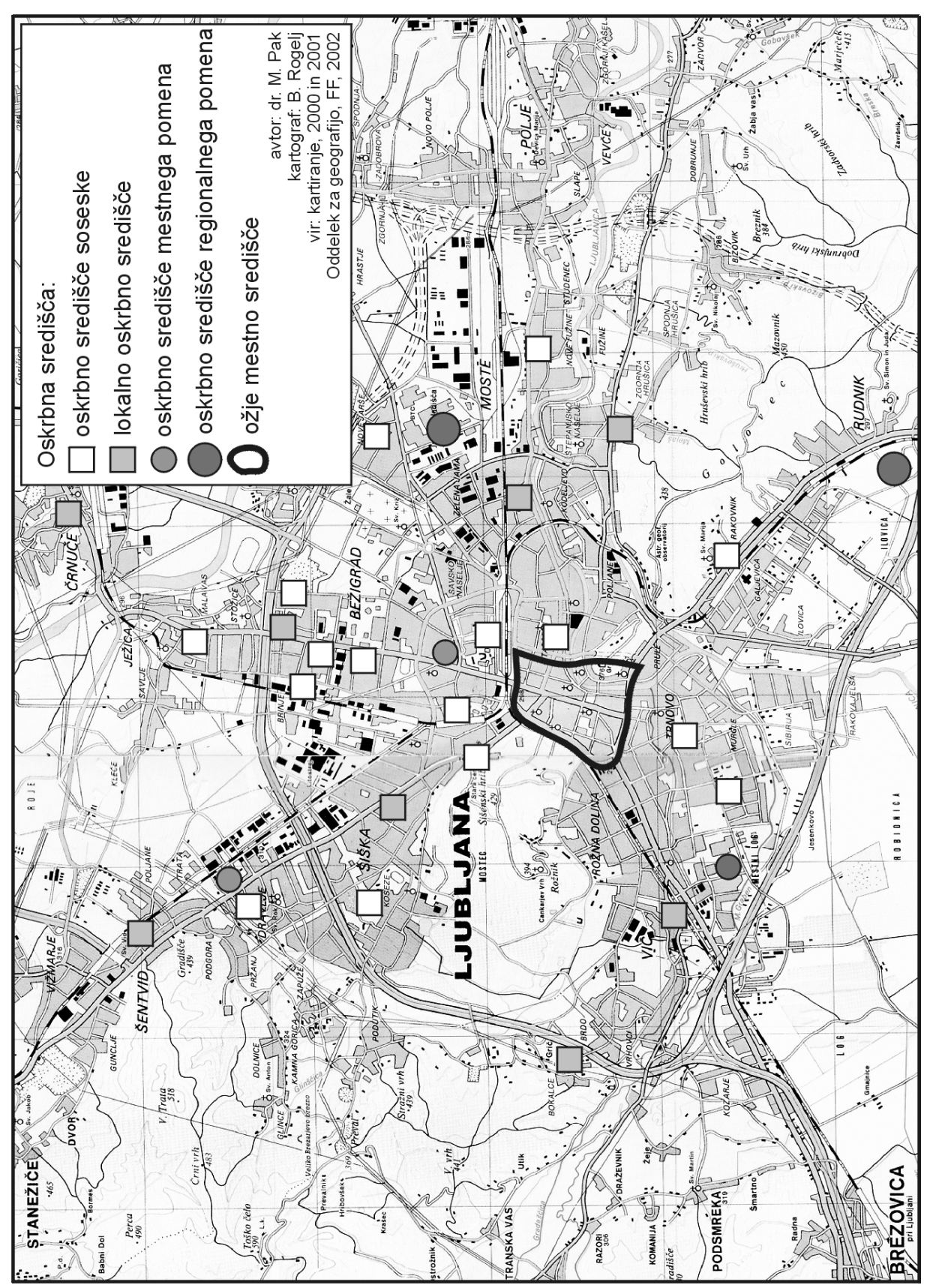

Karta 2: Oskrbnih središč v Ljubljani je vedno več. 


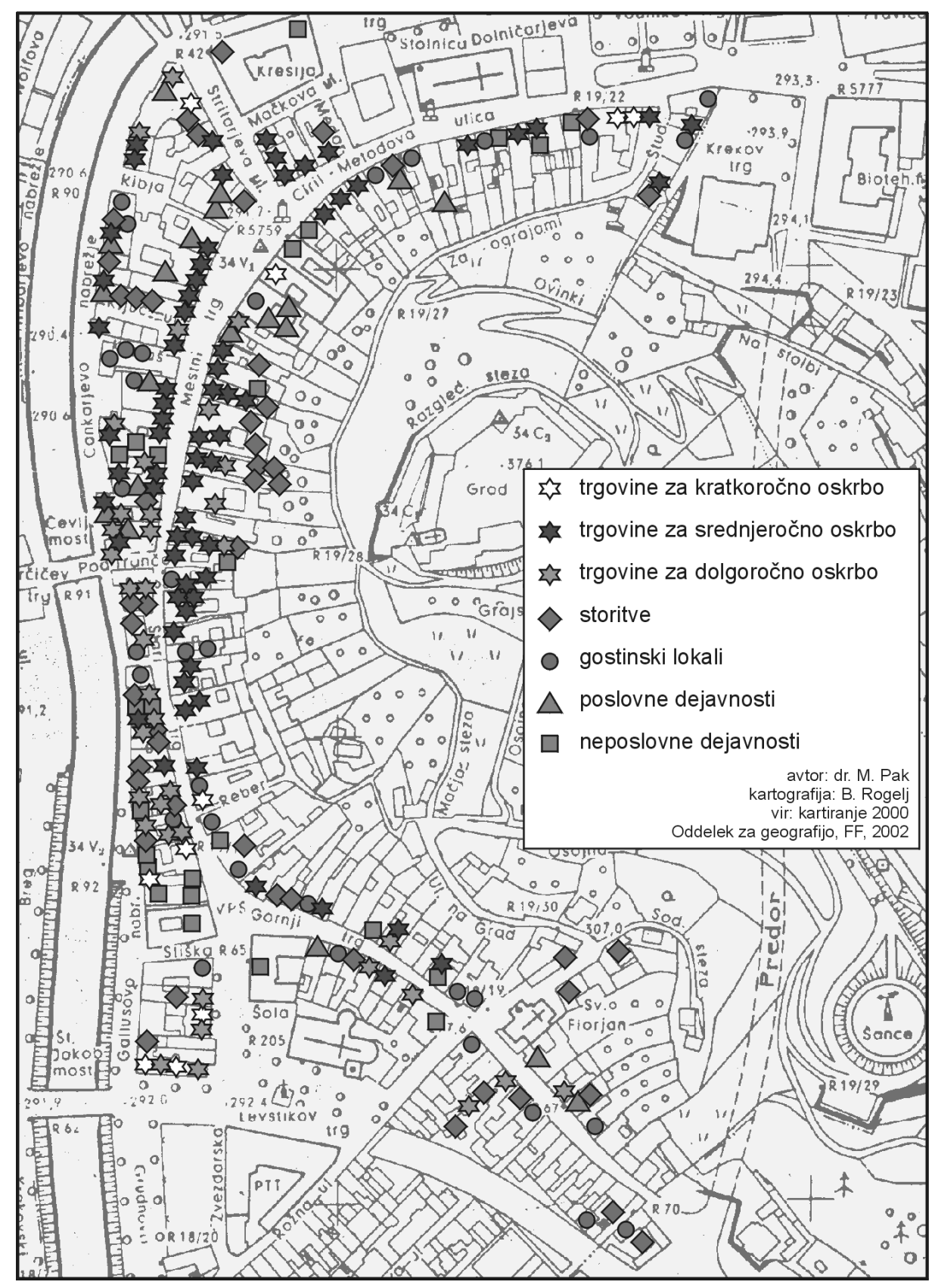

Karta 3: Funkcijska pestrost v srednjeveškem jedru Ljubljane. 
Omeniti velja še širjenje državne uprave, zanimiv pa je tudi razvoj, oziroma širjenje nekaterih drugih nadregionalno pomembnih dejavnosti, kot sta zdravstvena in univerzitetna. Slednja na šestih pomembnejših lokacijah vedno hitreje razvija tudi svojo infrastrukturo. Tako je v okolici fakultet že najmanj $50 \%$ obratov v celoti ali prevladujoče namenjenih študentom in zaposlenim na Univerzi. Glede na to je vpliv obeh dejavnosti na mestno ekonomijo neposredno ali posredno izredno pomemben.

Končno je treba še izpostaviti v Ljubljani glavne mestne vpadnice, ob katerih se v zadnjih letih naseljujejo številne dejavnosti. Zlasti ob Celovški cesti se krepi trgovska funkcija, ob Dunajski cesti poslovno-oskrbno-storitvena in ob Tržaški cesti storitvena.

\subsection{Prostorski razvoj mest}

Podobni procesi kot $\mathrm{v}$ drugih evropskih mestih prednjačijo tudi $\mathrm{v}$ slovenskih mestih z vsemi posebnostmi, ki jih prinaša prehod iz socialističnega $v$ kapitalistično ekonomijo. $\mathrm{V}$ primerjavi s prvimi gre $\mathrm{v}$ naših mestih za šibkejšo suburbanizacijo in za najmanj podobno intenzivne prostorske spremembe na sklenjeno pozidanem mestnem teritoriju. Pozidava na sklenjeno pozidanem mestnem teritoriju se s pozidavo praznih ali sproščenih površin zgošča. To se dogaja tudi v mestnem središču Ljubljane, zlasti na njegovem obrobju. Še močnejšo gradbeno dejavnost doživlja širše obrobje mestnega središča, pa tudi obrobje mesta samega. In ker gre za gradnjo stanovanjskih objektov in za gradnjo vsakovrstnih nestanovanjskih objektov, postaja raba mestnih površin vedno bolj heterogena. Tudi stanovanjska pozidava je vedno bolj pestra. Nadstandardne večstanovanjske stavbe in razkošne enodružinske hiše se gradijo povsod tam, kjer je na voljo prostor, tudi v slabih ekoloških okoljih (ob avtocestah) ali na najslabšem zemljišči (na Barju). Tudi raba v preteklosti dokaj homogenih proizvodnih in storitvenih površin postaja vedno bolj pestra, saj so na isti lokaciji oskrbni, storitveni in proizvodni obrati.

Mesta rastejo tudi navzven, pri čemer so oskrbna središča najbolj viden element mestne ekspanzije, ki jim je treba prišteti še določene servisne dejavnosti, med katerimi še posebej

izstopajo avtomobilski saloni. V Ljubljani je tipičen tovrstni primer BTC, podobnih manjših primerov pa je $\mathrm{v}$ naših mestih še veliko. $\mathrm{V}$ ta proces sodi tudi suburbanizacija obmestij, ki gre danes $\mathrm{v}$ smeri ekspanzije stanovanjske in nestanovanjskih funkcij. V ljubljanskem suburbanem obrobju je že $9 \%$ vseh delovnih mest ljubljanske mestne regije, kar je le za polovico manj glede na število prebivalstva, kot je to v samem mestu (Ravbar, 2002). In ker mestna regija vključuje tudi večja ali manjša lokalna središča, ta v ekonomskem po- 
gledu vedno bolj postajajo del središčnega mesta, v našem primeru Ljubljane. Od Ljubljane je v veliki meri odvisen razvoj Grosuplja, Domžal, Kamnika, Mengša, Vrhnike in drugih središč.

\section{SKLEP}

Tudi slovenska mesta vse bolj izgubljajo klasično zgradbo, ki je glede na razvojne dejavnike opredeljena z različnimi modeli. Mesta so tudi že presegla večjederni model svoje zgradbe, postajajo ekstremno heterogena. Lahko tudi ugotovimo vedno večjo razdrobljenost jeder in seveda vedno večje prepletanje bivalne in številnih drugih funkcij. Vrednost, funkcije in izgled posameznih mestnih predelov se spreminja. Kam se hodijo Mariborčani oskrbovat? V preteklosti so oskrbni tokovi vodili na levi breg Drave, danes na levi breg in celo na obrobje mesta. Ljubljančani se oskrbujejo na mestnem obrobju, tudi $\mathrm{v}$ kino hodijo že v BTC. Ali središča naših mest izgubljajo na pomenu in vrednosti. Promet po Gosposki cesti in na Grajskem trgu v Mariboru sta minimalna. Ali ni tu iskati tudi ne zanimanje za izvajanje načrtovane sanacije, v celotnem območju znotraj nekdanjega mestnega obzidja, ki znatneje ni segla niti do Koroške ceste? V Ljubljani je del takšnega procesa nedvomno zaprtje Metalke in samo vprašanje časa je zapiranje številnih drugih trgovin, ki jih bodo verjetno zasedle večje in ekonomsko močnejše ter investicijsko sposobnejše trgovske verige ter druge dejavnosti. Ali bosta mariborski Lent in ljubljansko srednjeveško mestno jedro "živela" v glavnem od prostočasovnih aktivnosti, oziroma potrošnje domačega prebivalstva in od turistov. Kako povečati trgovsko privlačnost mestnih središč, ko na robu mest še kar nastajajo nove nakupovalne površine. To so le nekateri problemi in vprašanja smotrnega socialnega, funkcijskega in zgradbenega (morfološkega) razvoja naših mest.

Ali in kako lahko geografija prispeva $\mathrm{k}$ reševanju razvojnih problemov mest, oziroma k njihovemu skladnejšemu razvoju? Zdi se, da podobno kot $\mathrm{v}$ drugih okoljih tudi v mestih primanjkuje točnega poznavanja rabe prostora. Drugo so vsekakor procesi, ki so kompleksni, odvisni od vrste dejavnikov. Vsekakor je nujno ravnotežje med prostorom, njegovo rabo, ekonomiko in socialno zgradbo. Vse to so elementi, ki jih geografska proučevanja zaradi svojega kompleksnega pogleda in večinoma tudi pristopa, lahko najbolje realno osvetli. Predvsem pa se je treba vključiti v neposredno načrtovanje skladnega razvoja mest. 


\section{Literatura:}

Holzner, L., 2001, Amerikanismen in deutschen Staedten. Praxis Geographie, 2001/5, Braunschweig, s. 24-30.

Pak, M., 2002, Funkcijska zgradba Ljubljane. Geografija Ljubljane, Ljubljana 2002, s.133-149.

Ravbar, M., 2002, Suburbanizacijske težnje v razvoju prebivalstva in delovnih mest v ljubljanski mestni regiji. Geografija Ljubljane, Ljubljana, 2002, s. 215-233.

Zehner, K., 2002, Megastedte - Weltstaedte - Hauptstaedte. Praxis Geographie, 2002/10, Braunschweig, s. 4-9.

\section{CITY AT TRANSITION}

\section{Summary}

Also Slovene cities are characterised by brisk structural and spatial changes. These are being expecially intensive due to full enforcement of economic factors in social and functional structure as well as in activities which affect the environment. In bigger cities this process is much stronger (bigger, faster, more intensive), in particular in Ljubljana, the capital function of which resulted in numerous new development factors gained. Otherwise, with regard to importance of their role in development of cities, the following factors are pointing out: transition to market economy, denationalisation and reprivatisation, investment policy, private initiative, and others.

In general, functional variability of cities is more and more expressed, residential and others, supply, servicing and productional functions are becoming significantly spatially mixed. However, although the quality of residential environment (air, noise and communal and supply function) is improving in general, free and abandoned surfaces (military, industrial, constructional) are being built-up therefore building-up is becoming more and more intensive in cities, city centres, at outskirts and in suburbs. Besides economic changes, all these processes are connected also with the changed value of the city space.

Social structure of Slovene cities is becoming more and more heterogenious, which holds good for the whole city territory. Building of over-standard appartments and new, smaller, quality settlements of block of flats is in expansion, which is in great deal depending on available surfaces, more often at the continuously built city territory than at the outskirt thereof. However in the functional respect, expansion of tertiarry activities lead to increased number of 
supply centres of different sizes. In Ljubljana, four the biggest concentrations of big domestic anf foreign trade houses took over supply of the main part of the city's inhabitants and of the whole urbane region. However the biggest among these BTC (Trade Center) have become real trade cities occupying over $300,000 \mathrm{~m}^{2}$ of selling surfaces. 